\title{
Molecular Basis of Heavy-Chain Class Switching and Switch Region Deletion in an Abelson Virus-Transformed Cell Line
}

\author{
RONALD DEPINHO, ${ }^{1}$ KELLY KRUGER, ${ }^{1}$ NANCY ANDREWS,${ }^{2}$ STUART LUTZKER, ${ }^{1}$ \\ DAVID BALTIMORE, ${ }^{2}$ AND FREDERICK W. ALT ${ }^{1 *}$ \\ Department of Biochemistry and Institute for Cancer Research, Columbia University, College of Physicians and \\ Surgeons, New York, New York 10032, ${ }^{1}$ and Whitehead Institute for Biomedical Research, Cambridge, \\ Massachusetts $02142^{2}$
}

Received 13 June 1984/Accepted 25 September 1984

\begin{abstract}
We demonstrated that a subclone of an Abelson murine leukemia virus-transformed B-lymphoid cell line switched from $\mu$ to $\gamma_{2 b}$ expression in vitro, by the classical recombination-deletion mechanism. In this line, the expressed $V_{H} D J_{H}$ region and the $C_{\gamma 2 b}$ constant region gene were juxtaposed by a recombination event which linked the highly repetitive portions of the $S_{\mu}$ and $S_{\gamma 2 b}$ regions and resulted in the loss of the $C_{\mu}$ gene from the intervening region. An additional recombination event in this subclone involved an internal deletion in the $S_{\mu}$ region of the expressed (switched) allele. One end of this deletion occurred very close to the switch recombination point. Despite the recombination-deletion mechanism of switching, the $\gamma_{2 b}$-producing line retained two copies of the $C_{\mu}$ gene and two copies of the sequence just $5^{\prime}$ to the $S_{\gamma 2 b}$ recombination point. The possible significance of the retention of these sequences to the mechanism of class switching is discussed.
\end{abstract}

During the differentiation of a B-lymphocyte to a plasma cell, the class of immunoglobulin produced by its progeny may change from immunoglobulin $\mathrm{M}$ (IgM) and IgD to a different class (e.g., an IgG or IgA), while maintaining the same variable region specificity $(13,32)$. This phenomenon, termed heavy-chain class switching, allows a single clone of B-cells to generate progeny which maintain the same antigen-binding specificity $\left(\mathrm{V}_{\mathrm{H}}\right)$ linked to different $\mathrm{C}_{\mathrm{H}}$ effector functions.

The order of the $C_{H}$ genes has been determined to be $5^{\prime}-\left(\mathrm{V}_{\mathrm{H}} \mathrm{DJ}_{\mathrm{H}}\right)-\mathrm{C}_{\mu}-\mathrm{C}_{\delta}-\mathrm{C}_{\gamma 3}-\mathrm{C}_{\gamma 1}-\mathrm{C}_{\gamma 2 \mathrm{~b}}-\mathrm{C}_{\gamma 2 \mathrm{a}}-\mathrm{C}_{\varepsilon}-\mathrm{C}_{\alpha}-3^{\prime}$ (38). Much of our current knowledge of the molecular basis of heavychain class switching has come from comparative studies of heavy-chain gene structure in independently derived immunoglobulin-secreting myeloma tumors $(25,37)$. These studies have indicated that the switch process is often effected by a recombination-deletion mechanism distinct from that involved in $\mathrm{V}_{\mathrm{H}} \mathrm{DJ}_{\mathrm{H}}$ joining $(2,3,25,37)$. Expression of a given downstream $C_{H}$ gene in a myeloma results from juxtaposition of the $C_{H}$ gene to the expressed $V_{H} D J_{H}$ complex by deletion of the intervening DNA sequence, including the $C_{\mu}$, and any other intervening $C_{H}$ genes $(12,14$, 23,42 ). This process has been proposed to be mediated by a set of repeated sequences ( $S$ regions) which lie several kilobases $(\mathrm{kb}) 5^{\prime}$ to each $\mathrm{C}_{\mathrm{H}}$ gene $(24,28)$. In its most simple form, switching could occur by direct joining of the switch recombination sequence $5^{\prime}$ to $C_{\mu}$ to those $5^{\prime}$ to the expressed $\mathrm{C}_{\mathrm{H}}$ gene, resulting in a linear deletion of the intervening DNA (subsequently referred to as a classical recombinationdeletion mechanism). However, the occurrence of switch recombination sequences from both upstream and downstream $\mathrm{C}_{\mathrm{H}}$ genes $5^{\prime}$ to an expressed $\gamma_{1}$ gene of a myeloma indicates that the process, at least occasionally, may be more complicated $(15,31)$. Various models for class switching have been proposed to accommodate the complicated structures, including unequal exchanges between sister chromatids or chromosomes $(15,31)$.

\footnotetext{
* Corresponding author.
}

The 18-81A2 line is a $\gamma_{2 b}$-producing derivative of the $\mu$-producing 18-8 Abelson murine leukemia virus (A-MuLV)transformed cell line. We have previously shown that this subclone produces $\gamma_{2 b}$ heavy chains containing a variable region sequence which derives from the same $\mathrm{V}_{\mathrm{H}} \mathrm{DJ}_{\mathrm{H}^{-} \text {-rear- }}$ ranged heavy-chain allele that is used for $\mu$ heavy-chain production by the parental line (5). The A2 line also has a $\mathrm{V}_{\mathrm{H}} \mathrm{DJ}_{\mathrm{H}}$ rearrangement at its other heavy-chain allele, but this rearrangement is nonfunctional due to an in-phase termination codon in the $\mathrm{D}$ segment (6). Because the $\mathrm{A}-2$ line apparently contained two copies of the $C_{\mu}$ gene, we suggested that the switch to $\gamma_{2 b}$ production in this line might have occurred, at least in part, by a differential RNA-processing mechanism (5) similar to that used for the simultaneous expression of $\mu$ and $\delta$ by B-lymphocytes $(20,23,27)$. In this report, we demonstrate that although the A2 line clearly retains two copies of the $C_{\mu}$ gene as well as two copies of $\mathrm{S}_{\gamma_{2} \mathrm{~b}}$ sequences, the class switch in this line occurs by the classical recombination-deletion mechanism.

\section{MATERIALS AND METHODS}

Cells. Cell lines were grown as a suspension in RPMI medium supplemented with $10 \%$ heat-inactivated fetal calf serum and $0.0004 \%$ (vol/vol) 2-mercaptoethanol. Subcloning of cell lines was performed by plating at limiting dilution in microtiter wells. Further details about the growth and characteristics of the lines have been presented elsewhere $(5,7)$.

Analysis of heavy-chain gene organization. DNA preparation, restriction enzyme digestions, agarose gel electrophoresis, DNA blotting procedures, probe preparations, and hybridization procedures were performed as described previously $(7,22)$. The $C_{\mu}$-probe was prepared from the 1,250 base-pair (bp) insert of pAB $\mu-8$ (4). The $J_{H}$ probe was prepared from the 3 '-terminal $700 \mathrm{bp}$ of the 6.2-kb EcoRI containing the germ line $J_{H}$ segments (8), and the $5^{\prime}$ - and $3^{\prime}-S_{\gamma 2 b}$ probes were prepared from the 0.8 - and $1.2-\mathrm{kb}$ $E c o$ RI- $B g$ III fragments, respectively, derived from the $4.1-\mathrm{kb}$ $E c o R I S_{\gamma 2 b}$ portion of the genomic clone, SL1 (39) (see Fig. 2A). Further details are described in the figure legends. 


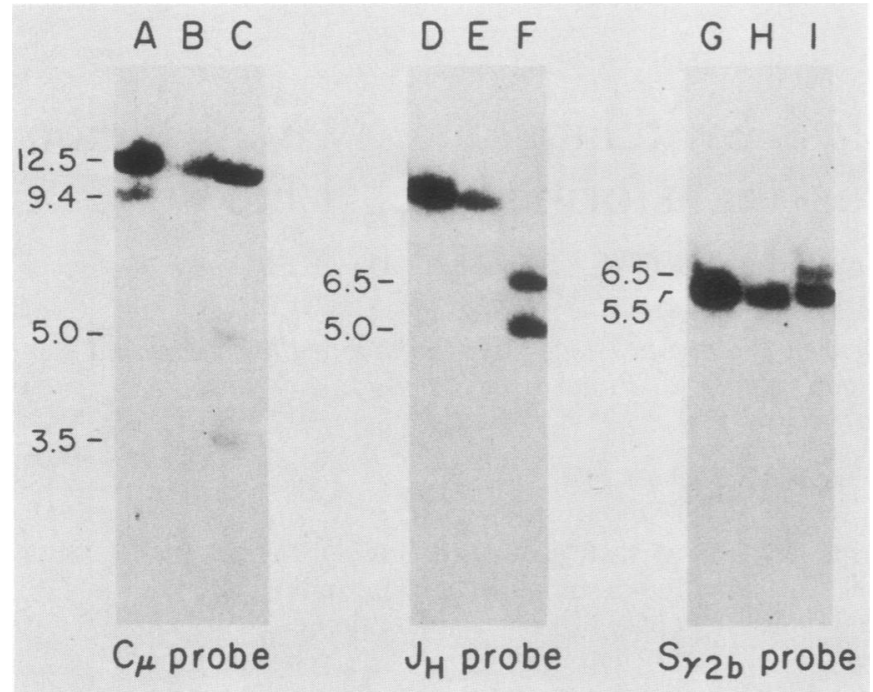

FIG. 1. Heavy-chain gene organization in A-MuLV transformants. Approximately $10 \mu \mathrm{g}$ of genomic DNA from mouse liver (lanes A, D and G), 18-8 (lanes B, E and H), and A-2 (lanes C, F and I) was digested with BamHI, fractionated by electrophoresis through $1.0 \%$ agarose gels, and blotted to nitrocellulose paper; duplicate filters were assayed respectively for hybridization to the ${ }^{32} \mathrm{P}$-labeled inserts from $\mathrm{pAB} \mu-1\left(\mathrm{C}_{\mu}\right.$ probe, lanes $\mathrm{A}$ through $\left.\mathrm{C}\right), \mathrm{PJ}_{\mathrm{H}} 800\left(\mathrm{~J}_{\mathrm{H}}\right.$ probe, lanes D through F), or 3' $S_{\gamma 2 b}$ probe (lanes G through I).

Genomic cloning and DNA sequencing. Genomic libraries were constructed by cloning an $M b o I$ partial digest of genomic DNA from the 18-81 A2 line into the lambda phage vector Charon 30 (34) as described by Blattner et al. (10). Recombinant phage were screened by the method of Benton and Davis (9) for hybridization to $J_{H}$ and $3^{\prime}-S_{\gamma 2 b}$ probes. Plaques hybridizing to both probes were purified, and appro- priate portions of the inserts were subcloned into pBR322 and mapped by digestion with various restriction enzymes as described previously (6). Various regions of the inserts were sequenced by the method of Maxam and Gilbert (26) as previously described (6). For further details, see the legends to Fig. 2 and 3.

\section{RESULTS}

The class switch in the $\mathrm{A} 2$ line is accompanied by the movement of the $S_{\gamma 2 b}$ region into close proximity with the expressed $V_{H}$ region. The nature of the DNA alterations that accompanied the class switch was studied in the following manner. Genomic DNAs from liver, 18-8, and A-2 were digested with various restriction endonucleases, fractionated by agarose gel electrophoresis, and transferred to nitrocellulose paper, and duplicate filters were assayed for hybridization to ${ }^{32}$ P-labeled $C_{\mu}, J_{H}$, and $3^{\prime}-S_{\gamma 2 b}$ probes (Fig. 1). Bam HI cuts between $\mathrm{J}_{\mathrm{H}} 2$ and $\mathrm{J}_{\mathrm{H}} 3$ and in the middle of the second $C_{\mu}$ exon but not in the intervening region (Fig. 2) (6). Thus, BamHI-digested liver DNA displayed a $\mathrm{C}_{\mu}$-positive fragment of $12.5 \mathrm{~kb}$, which corresponds to the sequences $3^{\prime}$ to the BamHI site in $\mathrm{C}_{\mu}$, as well as a $9.4-\mathrm{kb}$ fragment that contained the $5^{\prime}$ portion of the $C_{\mu}$-coding region and the $3^{\prime}$ portion of the $J_{H}$ region (Fig. 1, compare lanes $A$ and $D$ ). When assayed with the $J_{H}$ and $C_{\mu}$ probes, DNA from the parental 18-8 line was found to have a hybridization pattern that was essentially identical to that of liver DNA, i.e., no obviously rearranged bands (Fig. 1, lanes $B$ and $E$; the 9.4-kb band in lane $B$ was more evident in longer exposures). This result can be explained by the fact that the $V_{H}$ segment of the productive $\mathrm{V}_{\mathrm{H}} \mathrm{DJ}_{\mathrm{H}}$ 3-rearranged allele of 18-8 (A2) has a BamHI site ca. 250 bp from the joint, whereas the nonproductive allele contains a $\mathrm{V}_{\mathrm{H}} \mathrm{DJ}_{\mathrm{H}} 2$ rearrangement (6) (Fig. 2A). Thus, the nonproductive allele will yield an embryonic fragment which hybridizes to the $J_{H}$ and $C_{\mu}$

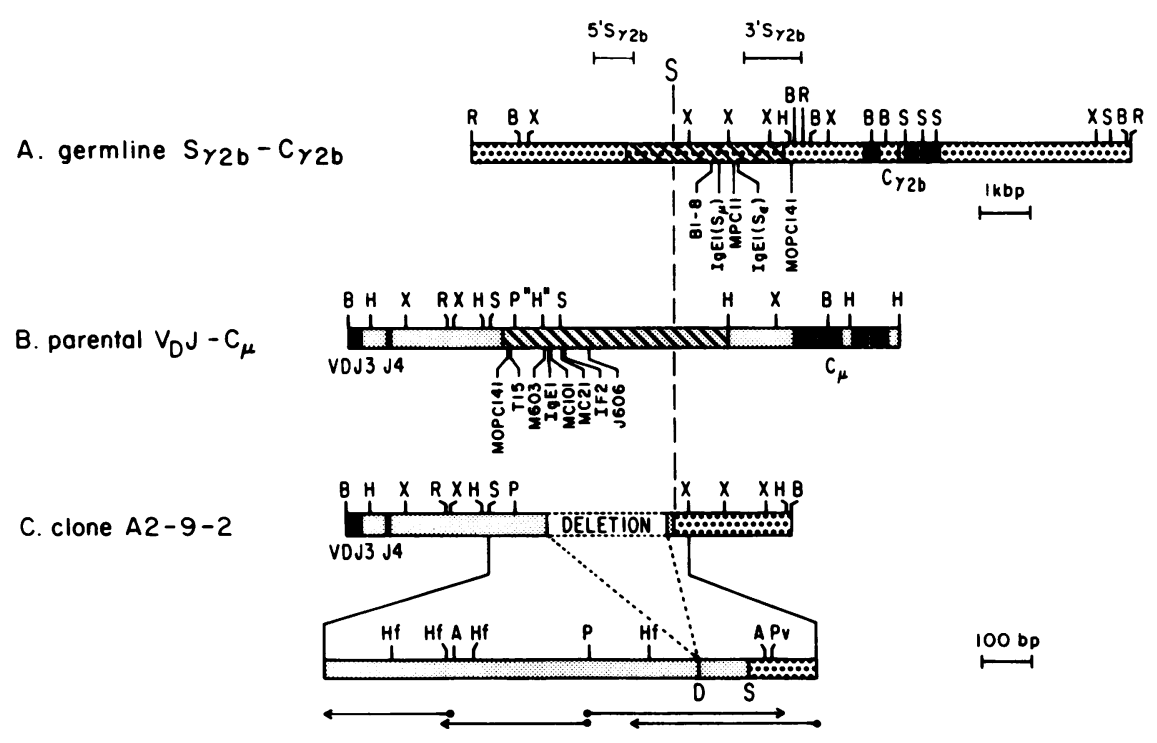

FIG. 2. Structure of the $S_{\mu}-S_{\gamma 2 b}$ rearrangement in the A2 line. (A) Partial restriction map of the genomic $S_{\gamma 2 b}$ region. (B) Partial restriction endonuclease map of the parental VDJ- $C_{\mu}$ region. (C) Partial restriction map of the BamHI insert fragment of clone 9-2-1 which was derived from genomic DNA of line $A 2$ and contains the expressed $V_{H} D J_{H}$ region and $S_{\gamma 2 b}$ sequences. The presence of the $S_{\mu}$ and $S_{\gamma 2 b}$ sequences in the noted regions of the clone has been confirmed by direct DNA sequence analysis (Fig. 3). Horizontal arrows represent sequencing strategy. The region noted $D$ contains the point of intra- $S_{\mu}$ deletion. The vertical line labeled $S$ indicates the recombination site between the $S_{\mu}$ and $\mathrm{S}_{\gamma 2 \mathrm{~b}}$ regions. Cross-hatched areas correspond to switch regions, and blackened sites indicate $\mathrm{C}_{H}$ exons. Previously reported switch recombination events in the $S_{\mu}$ and $S_{\gamma 2 b}$ regions are indicated in panels $A$ and $B$ by the names of the lines in which they occurred. This information was obtained from published sources $(16,18,19,21,28-31,36,40)$. A 2.4-kb deletion within the $S_{\mu}$ region is also indicated in panel C. The location of the 0.8-kb 5'-S $\mathrm{S}_{\gamma 2 \mathrm{~b}}$ and 1.2-kb 3'-S $\mathrm{S}_{\gamma 2 \mathrm{~b}}$ probes are represented above panel A. R, EcoRI; B, BamHI; H, HindIII; S, SacI; X, XbaI; Hf, HinfI; A, AvaII; and P, PvuII. 
probes when cleaved with $\mathrm{BamHI}$ (because the BamHI site lies between $\mathrm{J}_{\mathrm{H}} 2$ and $\mathrm{J}_{\mathrm{H}} 3$ ), and the productive allele will yield a fragment of similar size because the BamHI site lost in the $\mathrm{V}_{\mathrm{H}} \mathrm{DJ}_{\mathrm{H}} 3$ join is restored by a similarly positioned BamHI site (relative to $J_{H} 3$ ) in the $V$ segment (Fig. 2A). BamHI-digested DNA from the A2 ( $\gamma_{2 b}$-producing) subclone revealed two novel fragments of 6.5 and $5.0 \mathrm{~kb}$, which hybridized to the $J_{H}$ probe (Fig. 1, lane $F$ ). The $6.5-\mathrm{kb}$ fragment was shown to contain the productive $V_{H} D_{H}$ based on hybridization to a probe specific for the expressed $V_{H}$ gene (data not shown), whereas the smaller fragment presumably represented the $J_{H}$ 2-to- $C_{\mu}$ portion of the nonproductive allele. In the $\mathrm{A} 2$ subclone, both of these alleles contain large deletions in the $\mathrm{J}_{\mathbf{H}^{-}}$-to- $\mathrm{C}_{\mu}$ intron (see below and reference 5). When assayed with the $\mathrm{C}_{\mu}$ probe, BamHI-digested DNA from the A2 line revealed a novel fragment of $3.5 \mathrm{~kb}$ and a fragment of $5.0 \mathrm{~kb}$ which comigrated with the $\mathrm{J}_{\mathrm{H}}$-positive BamHI fragment corresponding to the nonexpressed allele, in addition to the 12.5 -kb fragment corresponding to the $3^{\prime} \mathrm{C}_{\mu}$ region (Fig. 1, lane $\mathrm{C}$ ). This result suggested that a rearrangement event had unlinked the $C_{\mu}$ gene segment from the expressed $V_{H} D J_{H}$ segment in the A2 subclone and that this $\mathrm{C}_{\mu}$ allele was retained in the cell in an altered context (i.e., the 3.5-kb Bam HI fragment).

To determine whether the apparent rearrangement between $J_{H}$ and $C_{\mu}$ on the productive allele of the A2 subclone was associated with the switch to $\gamma_{2 b}$ production in this line, we assayed BamHI-digested DNAs from the various lines for hybridization to a probe derived from the $3^{\prime}-S_{\gamma 2 b}$ region (see the legend to Fig. 2 for a description of the probe). Because the $S_{\gamma 2 b}$ switch region is contained within a $5.5-\mathrm{kb}$ BamHI fragment, a class switch event involving fusion of the $S_{\mu}$ and $S_{\gamma 2 b}$ regions should generate a novel BamHI fragment which hybridizes to both the $J_{H}$ and 3 ' $-S_{\gamma 2 b}$ probes. Although DNA from the parental 18-8 line contained only the 5.5-kb 3'-S $\mathrm{S}_{\gamma 2 \mathrm{~b}}$-positive Bam HI fragment observed in liver DNA (Fig. 1, lanes $G$ and $H$ ), DNA from the A2 subclone contained, in addition to a germ line fragment, a novel $6.5-\mathrm{kb}$ 3 '-S ${ }_{\gamma 2 b}$-positive $B a m H I$ fragment which comigrated with the $\mathbf{J}_{\mathbf{H}}$-positive BamHI fragment found in that line (Fig. 1, compare lanes $\mathrm{F}$ and $\mathrm{I}$ ). This result suggested that a rearrangement had occurred which brought the $J_{H}$ and $S_{\gamma 2 b}$ of the expressed allele of A2 into close proximity. Additional support for this conclusion was obtained by similar blotting analyses with other enzymes (data not shown).

The class switch event in the A2 line involved recombination between $S_{\mu}$ and $S_{\gamma 2 b}$ regions. The nature of the potential class switch recombination event suggested from the restriction mapping analyses was further analyzed as follows. Partial $M b o$ I digests of genomic DNA from the A2 line were cloned into Charon 30 , and clones were isolated which hybridized to both $\mathrm{J}_{\mathrm{H}^{-}}$and $3^{\prime}-\mathrm{S}_{\gamma 2 \mathrm{~b}}$-specific probes. A partial restriction endonuclease map of the internal $6.5-\mathrm{kb} \mathrm{BamHI}$ fragment (which comigrated with the $\mathrm{J}_{\mathrm{H}^{-}}$and $3^{\prime}-\mathrm{S}_{\gamma 2 \mathrm{~b}}$-positive $B a m H I$ fragment of the A2 line) of one such clone (A2-9-2) is presented in Fig. 2C. Comparison of the map of this clone to that of the embryonic $S_{\gamma 2 b}-C_{\gamma 2 b}$ region (Fig. $2 A$ ) and to that of the expressed $\mathrm{V}_{\mathrm{H}} \mathrm{DJ}_{\mathrm{H}}-\mathrm{C}_{\mu}$ region of the 18-8 parental line (Fig. 2B) clearly suggests that the class switch in the 18-8 line occurred by a recombination-deletion mechanism which resulted in the fusion of the $S_{\mu}$ and $S_{\gamma 2 b}$ sequences with removal of the intervening $\mathrm{C}_{\mathrm{H}}$ genes (including $\mathrm{C}_{\mu}$ ). We confirmed this interpretation by determining the nucleotide sequence of various regions of the clone to directly demonstrate the presence, at the indicated locations, of the expressed $V_{H} D J_{H}$ region of the parental 18-8 line $\left(V_{H} 81 Y\right.$ [5]) (data not shown), as well as the $S_{\mu}$ and $S_{\gamma 2 b}$ regions (see below).

A detailed analysis of the nucleotide sequence near the $S_{\mu}$-to- $S_{\gamma 2 b}$ joint in clone A2-9-2 indicated that the expressed heavy-chain allele of the A2 subclone contained two rearrangement events within the $S_{\mu}$ region: an internal deletion (indicated as D in Fig. 2 and 3), and a joining event between the highly repetitive portion of the $S_{\mu}$ region and the $S_{\gamma 2 b}$ region (indicated as $S$ in Fig. 2 and 3). Comparison of the sequence of clone A2-9-2 to that of the germ line $S_{\mu}$ region (Fig. 3, $S_{\mu} 5^{\prime}$ ) allowed us to locate the $5^{\prime}$ end of the deletion event within the $S$ region (see the legend to Fig. 3). However, although a small portion of the $S_{\mu}$ region located near and very homologous to that of the $3^{\prime}$ end of the deleted region has been sequenced (Fig. $3, S_{\mu} 3^{\prime}$ sequence), the highly repetitive nature of this portion of the $S_{\mu}$ region and the lack of extensive germ line sequence in this region preclude unequivocal identification of the exact germ line location of this end of the deletion. However, the unique repetitive structure of the A2-9-2 sequence 3 ' to the deletion point clearly identifies it as deriving from the highly repetitive portion of the $S_{\mu}$ region (28). For the same reason, we can also say that the switch recombination event occurred within the highly repetitive portion of the $S_{\mu}$ region; the location of this joint was ca. 100 bp downstream of the $3^{\prime}$ end of the internal deletion (Fig. 3). The switch recombination point upstream of the $\gamma_{2 b}$ gene could be located (Fig. 2B) and occurred in the unique 49 -bp repeat region that has previously been shown to be involved in switch recombination events in more mature cells (Fig. 3) (28). Four ambiguous bases, which could have been derived from either participating strand, occurred at the deletion joint, and one occurred at the switch recombination joint (Fig. 3, boxed sequences). Such ambiguous bases are frequently observed in D-to- $J_{H}$ joints (35).

The $A 2$ line retains two copies of the $C_{\mu}$ gene and two copies of upstream $S_{\gamma 2 b}$ sequences. Since switching occurred by the classical recombination-deletion mechanism in the 18-8 line, it was curious that this line apparently retained two copies of the $C_{\mu}$ gene (5). To confirm that the two distinct $C_{\mu}$ alleles occurred within the same cell, we assayed BamHI-digested genomic DNA from a series of subclones of the A2 line for hybridization to the $C_{\mu}$ probe. All of the subclones analyzed contained both the 5.0-kb $\mathrm{C}_{\mu}$-positive fragment which derived from the nonexpressed allele as well as the novel 3.5-kb $C_{\mu}$-positive fragment which was unlinked from the $J_{H}$ allele (Fig. 4).

The most interesting explanation for the retention of two $\mathrm{C}_{\mu}$ copies in $\mathrm{A} 2$ would be the retention by the cell of the DNA segment lying within the switch recombination points (see below). Such a mechanism would predict the retention of $S_{\gamma 2 b}$ sequences just 5' to the recombination point but in a rearranged form. To test this possibility we assayed Bam HIdigested DNAs from liver and A-2 cells for hybridization to a probe representing the region just upstream from the $S_{\gamma 2 b}$ switch recombination point (Fig. $2 A, 5$ ' $-S_{\gamma 2 b}$ probe). As indicated above, the $3^{\prime}-S_{\gamma 2 b}$ probe hybridized strongly to the 5.5-kb germ line Bam HI fragment from the unrearranged allele and to the rearranged fragment of $6.5 \mathrm{~kb}$ which contained the expressed $V_{H} D_{J_{H}}$ and the $S_{\mu}$ sequences (Fig. $5 A)$. The 5 '-S $S_{\gamma 2 b}$ probe also hybridized to the $5.5-\mathrm{kb}$ germ line fragment from the unrearranged allele and weakly to the rearranged $6.5-\mathrm{kb}$ fragment due to some $S_{\gamma 2 \mathrm{~b}}$ region homology at its 3' end (Fig. 2A); however, it hybridized strongly to a unique 3.5-kb BamHI fragment (Fig. 5B). Analyses with other enzymes gave similar results (data not shown). These 
$S_{\mu} 5^{\prime}$ aCTCTGAGgTAAGCAA AGCTGGGCTTGAGCCAAAATGAAGTAGACTGTAATGAACTGGAATGAGC

A2-9-2 ACTCT GAGGTAAGCAA AGCTG AGCTGAGCTGCGGTGAGCTGAGCTGAGATGGGGTAACCTGAGCT

$\mathrm{S}_{\mu} 3^{\prime}$ GAGCTGAGCTGGGGTG AGCTG AGCTGAGCTGGGGTGAGCT GAGCT GAGCTGGGGTGAGCTGAGCT

\author{
$S$

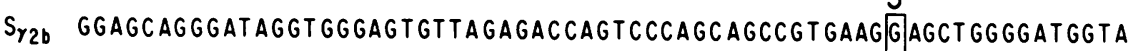 \\ A2-9-2 GAGCTGGGGTGAGCTGGGCTGAGCTGGGGTGAGCTGGGGTGAGTTGAGCT G AGCTTGGGATGGTA \\ $S_{\mu} 3^{\prime}$ GAGCTGGGGTGAGCTTGGCTGAGCTGGGGTGAGCTGGGGTGAGTTGAGCTGGGGTGAGCTGGGGT
}

\title{
SY2b GGAATATGAGGGACCAGTCTCAGC AGCTGTGGgGAAGCTGGGGCAGGTGGGAGTGTGAGGATCA \\ A2-9-2 GGAATATGAGGGACCAGTCTCAGCCAGCTGT GGGAAGCTGGGGCAGGTGGGAGTGTGAGGATCA
}

FIG. 3. The nucleotide sequence of S-region recombination events in the $A 2$ line. The nucleotide sequences of the germ line $S_{\mu}$ and $S_{\gamma 2 b}$ regions are compared with that of the corresponding region of the clone A2-9-2. The sequence of the A2-9-2 clone was determined by the method of Maxam and Gilbert by strategy outlined in Fig. $2 C$ (expanded region). $S_{\mu} 5^{\prime}$ represents the germ line $S_{\mu}$ sequence upstream from the $S_{\mu}$ deletion (reproduced from Nature [36], with permission). Our sequence analysis of $S_{\mu}$ actually extends ca. $1 \mathrm{~kb} 5^{\prime}$ to the presented region and demonstrated nearly complete homology with that reported by Sakano et al. $(36)$. $S_{\mu} 3^{\prime}$ refers to the germ line $S_{\mu}$ sequence $3^{\prime}$ to the site of the $S_{\mu}$ deletion and 5' to the point of recombination with the $S_{\gamma 2 b}$ region (reproduced from Nature [28], with permission). Although the sequence $3^{\prime}$ to the site of deletion and $5^{\prime}$ to the site of recombination is clearly derived from $S_{\mu}$, the highly repetitive nature of this portion of the $S_{\mu}$ region precludes unequivocal identification of the exact germ line location of this portion of the clone. The $S_{\gamma 2 b}$ sequence (reproduced from the Journal of Biological Chemistry [29], with permission) is just $5^{\prime}$ to the noted XbaI site. Recombination points D and S are described in the legend to Fig. 2.
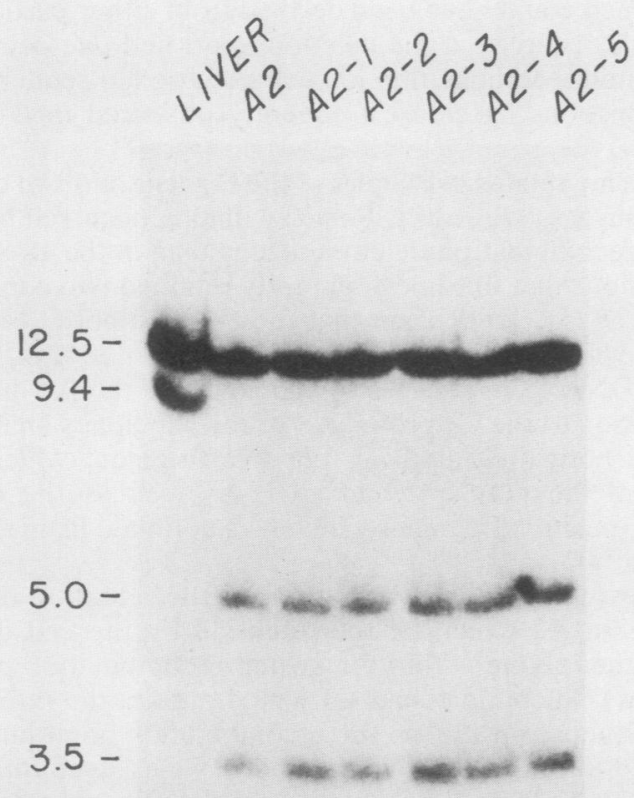

1234567

FIG. 4. Retention of two copies of the $C_{\mu}$ gene in subclones of line A2. The 18-81 A2 line was subcloned by plating at limiting dilution in microtiter wells. DNAs from mouse liver, the parent A2 line, and various subclones were digested with $\mathrm{BamHI}$ and analyzed for hybridization with the $C_{\mu}$ probe as described in the legend to Fig. 1 . results strongly suggest that the $S_{\gamma 2 b}$ sequences upstream from the switch recombination point were also retained in the cell but in a rearranged form. Thus, both sequences just downstream from the $S_{\mu}$ recombination point $\left(C_{\mu}\right)$ and just upstream from the $S_{\gamma 2 b}$ recombination point $\left(5^{\prime}-S_{\gamma 2 b}\right)$ appear to be retained in the cell in a rearranged form.

\section{DISCUSSION}

We demonstrated that the switch from $\mu$ to $\gamma_{2 b}$ production by the A2 subclone of the 18-8 line is accompanied by a rearrangement event which juxtaposed the $\gamma_{2 b}$ constant region gene segment to the expressed $\mathrm{V}_{\mathrm{H}} \mathrm{DJ}_{\mathrm{H}}$ segment. This recombination event occurred between sequences lying within the previously defined $S_{\mu}$ and $S_{\gamma 2 b}$ regions and was accompanied by the loss of the $C_{\mu}$ (and other $C_{H}$ ) genes from the segment of the expressed chromosome lying between $S_{\mu}$ and $S_{\gamma 2 b}$ but apparently not from the cell (see below). Both the mechanism of the switch in this line (recombination-deletion) and the fusion points of the switch recombination event (within $S_{H}$ regions) are consistent with the classical recombination-deletion model for class switching that was derived by analyzing the heavy-chain gene structure of various plasmacytomas and hybridomas.

We feel that the class switch-related events that we have observed do not represent the low-frequency, homologous recombination-mediated events observed in myelomas (17, 33) for multiple reasons, including the following. (i) The frequency of switching in these A-MuLV transformants is very high in some isolates $(5,11)$. (ii) The class switch events occurred between the $S$ region sequences, regions previously demonstrated to be involved in physiological class switch events. (iii) Like 18-8, all of the pre-B lines studied thus far have a predisposition to switch from $\mu$ to $\gamma_{2 b}$ (see below), and yet the $S_{\mu}$ and $S_{\gamma 2 b}$ regions are the most divergent $S$ region sequences; low-frequency class switch variants of myelomas usually occur between (closely related) subclasses $(17,33)$. (iv) The 18-8 line and other 
A-MuLV transformants which undergo class switch events also accumulate deletions in the $S_{\mu}$ region at high frequency (6; K. Kruger, M. G. Reth, G. D. Yancopoulos and F. W. Alt, manuscript in preparation); we now show that these deletions are within the same portion of the $S_{\mu}$ region that was involved in class switching. Significantly, more mature B-cell and T-cell lines do not appear to undergo this deletion activity during propagation $(5 ; \mathrm{K}$. Kruger and F. W. Alt, unpublished data).

Recently DNA blotting analyses of class switch events in several other 18-8 derivatives (11) and in an independently derived A-MuLV transformant which had undergone a class switch event (1) suggested that switching in those lines was also mediated by a deletion mechanism. In both of these studies, class switch events were analyzed only by Southern blotting $(1,11)$. In the former study, the exact area of the class switch recombination event was not localized (11). In the latter study, blotting data suggested that the site of recombination was $5^{\prime}$ to the $S_{\gamma 2 b}$ region, leading to the suggestion that switching in pre-B cells may occur outside the $S$ region (1); however, the exact nature of the recombination point and its relationship to $S$ region sequences were not determined. Our studies, on the other hand, clearly indicate that cultured pre-B cell lines can undergo $S$ regionmediated class switch recombination events. In confirmation of this conclusion, we have determined that a $\mu$ to $\gamma_{2 b}$ switch recombination event in an independent pre-B cell line (300-18) also occurred within the $S_{\gamma 2 b}$ region (G. D. Yancopoulos, R. DePinho, and F. W. Alt, manuscript in preparation). It is notable that like $A 2$, several other $18-8$ derivatives or independently derived A-MuLV transformants switch from $\mu$ to $\gamma_{2 b}(8,11$; G.D. Yancopoulos and F. W. Alt, manuscript in preparation). The molecular basis and physiological relevance of the predisposition of A-MuLV transformants to switch from $\mu$ to $\gamma_{2 b}$ remain to be determined. Since our current studies clearly indicate that the switch occurs between $S_{\mu}$ and $S_{\gamma 2 b}$ regions and since these are the most divergent $S$ region sequences $(28,29)$, it seems possible that high-frequency switching to $\gamma_{2 b}$ in pre-B cells may be characteristic of that developmental stage.

We have observed retention of two copies of the $C_{\mu}$ gene in subclones of the $\gamma_{2 b}$-producing $A 2$ line. In this line, the $C_{\mu}$ gene on the nonproductive allele remains in its original configuration (linked to the nonproductive $\mathrm{V}_{\mathrm{H}} \mathrm{DJ}_{\mathrm{H}}$ ), but the $\mathrm{C}_{\mu}$ gene which, presumably, was on the productive allele (the allele involved in the switch to $\gamma_{2 b}$ ) is retained in the cell but in a rearranged configuration, i.e., unlinked to $\mathrm{J}_{\mathrm{H}}$ (Fig. 1). Additional evidence for retention of the intervening sequences is provided by the retention of two copies of sequences just $5^{\prime}$ to the $S_{\gamma 2 b}$ switch recombination point, one of which was retained in a rearranged context (Fig. 5). Assuming that these retained, rearranged sequences are products of the same event, there are several likely mechanisms to explain their retention, including the following: (i) reintegration of the intervening DNA sequences which were excised as a result of $S_{\mu}-S_{y 2 b}$ recombination occurring between two genes of the same chromosome, although it should be noted in the context of such a mechanism that the intervening DNA sequences that are excised as a result of intrachromosomal D-to- $\mathrm{J}_{\mathrm{H}}$ or $\mathrm{V}_{\mathrm{H}^{-}}$-to- $\mathrm{DJ}_{\mathrm{H}}$ recombination have never been observed to be retained by the cell (8); and (ii) retention in the cell as a result of class switch recombination between $S_{\mu}$ and $S_{y 2 b}$ sequences on sister chromatids or homologous chromosomes. Both sister chromatid and homologous chromosome recombination models have been invoked to explain class switch events $(12,15,31)$, although

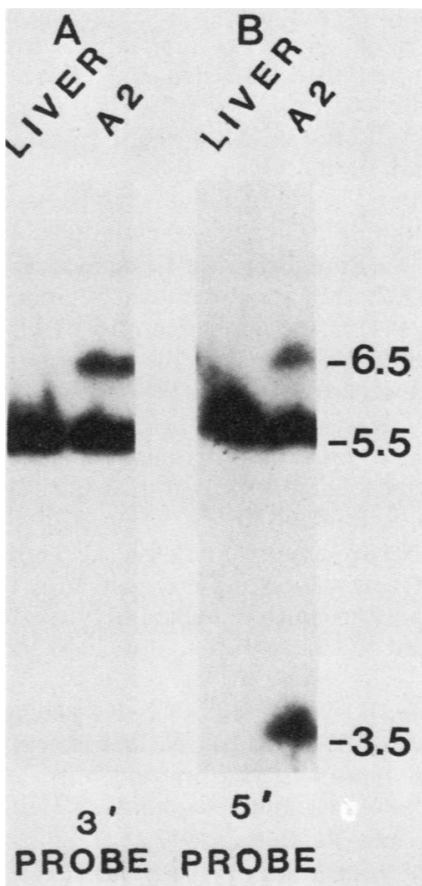

FIG. 5. Retention of $S_{\gamma 2 b}$ sequences upstream of the recombination point. DNA from liver and the A-2 line was digested with $B a m \mathrm{HI}$, processed as indicated in the legend to Fig. 1, and assayed for hybridization to the $3^{\prime}-S_{\gamma 2 b}(A)$ or $5^{\prime}-S_{\gamma 2 b}$ (B) probes.

no direct evidence in support of either of these models is currently available. The retention of the intervening sequence is consistent with a class switch event involving a homologous chromosome exchange. Retained intervening sequences are not directly consistent with a sister chromatid exchange model but could have resulted from a previous class switch event involving sister chromatids as proposed to explain the retention of upstream sequences in cells that have undergone $\mathrm{V}_{\mathrm{K}}$-to- $\mathrm{J}_{\mathrm{K}}$ joining of both chromosomes (41). We have observed retention of two copies of the $C_{\mu}$ gene in at least one other $\mathrm{A}-\mathrm{MuLV}$ transformant that appears to have undergone a class switch event (K. Kruger, G. D. Yancopoulos and F. W. Alt, unpublished data), although deletion of the $C_{\mu}$ gene was observed to accompany class switch events in other A-MuLV transformants $(1,11 ; \mathrm{G}$. D. Yancopoulos, R. DePinho and F. W. Alt, manuscript in preparation). Although the physiological significance of the retained intervening sequences in $\gamma_{2 b}$-producing $\mathrm{A}-\mathrm{MuLV}$ transformants is presently unclear, resolution of the possible mechanisms underlying this phenomenon could provide valuable insight into the molecular details of the class switch process.

\section{ACKNOWLEDGMENTS}

We thank K. Marcu for providing the SL1 clone from which the 5'and $3^{\prime}-S_{y_{2} b}$ probes were derived and $\mathrm{K}$. Blackwell for critically reading this manuscript.

This work was supported by American Cancer Society grants NP-393 (F.W.A.) and MV-34M (D.B.). F.W.A. is a recipient of an Irma T. Hirschl Career Scientist Award.

\section{LITERATURE CITED}

1. Akira, S., H. Sugiyama, N. Yoshida, H. Kikutani, Y. Yamamura, and T. Kishimoto. 1983. Isotype switching in murine pre-B cell lines. Cell 34:545-556.

2. Alt, F. W. 1983. The ordered sequence of Ig gene rearrangements. J. Mol. Cell. Immunol. 1:39-41. 
3. Alt, F. W., and D. Baltimore. 1982. Joining of immunoglobulin heavy-chain gene segments: implications from a chromosome with evidence of three $D-J_{H}$ fusions. Proc. Natl. Acad. Sci. U.S.A. 79:4118-4222.

4. Alt, F. W., A. Bothwell, M. Knapp, E. Siden, E. Mather, M. Koshland, and D. Baltimore. 1980. Synthesis of secreted and membrane-bound immunoglobulin mu heavy-chains is directed by mRNAs that differ at their 3 '-ends. Cell 20:293-301.

5. Alt, F. W., N. Rosenberg, R. Casanova, E. Thomas, and D. Baltimore. 1982. Immunoglobulin heavy-chain class switching and lipopolysaccharide-dependent heavy-chain expression in derivatives of an Abelson murine leukemia virus-transformed cell line. Nature (London) 296:325-331.

6. Alt, F. W., N. Rosenberg, V. Enea, E. Siden, and D. Baltimore. 1982. Multiple immunoglobulin heavy-chain gene transcripts in Abelson murine leukemia virus-transformed lymphoid cell lines. Mol. Cell. Biol. 2:386-400.

7. Alt, F. W., N. Rosenberg, S. Lewis, E. Thomas, and D. Baltimore. 1981. Organization and reorganization of immunoglobulin genes in Abelson murine leukemia virus-transformed cells: rearrangement of heavy but not light chain genes. Cell 27:381-390.

8. Alt, F. W., G. D. Yancopoulos, T. K. Blackwell, C. Wood, E. Thomas, M. Boss, R. Coffman, N. Rosenberg, S. Tonegawa, and D. Baltimore. 1984. Ordered rearrangement of immunoglobulin heavy-chain variable region segments. EMBO J. 3:1209-1219.

9. Benton, W., and R. Davis. 1977. Screening $\lambda$ gt recombinant clones by hybridization to single plaques in situ. Science 196:180-182.

10. Blattner, F. R., B. G. Williams, A. E. Blechl, K. DennistonThompson, H. E. Faber, L. Furlong, D. J. Grunwald, D. P. Kiefer, D. D. Moore, J. W. Schumm, E. L. Sheldon, and 0. Smithies. 1977. Charon phages: safer derivatives of bacteriophage lambda for DNA cloning. Science 196:161-169.

11. Burrows, P. D., G. B. Beck-Engeser, and M. R. Wabl. 1983. Immunoglobulin heavy-chain class switching in a pre-B cell line is accompanied by DNA rearrangement. Nature (London) 306:243-246.

12. Coleclough, C., D. Cooper, and R. P. Perry. 1983. Rearrangement of immunoglobulin heavy-chain genes during B-lymphocyte development as revealed by studies of mouse plasma cells. Proc. Natl. Acad. Sci. U.S.A. 77:1422-1426.

13. Cooper, M. D., J. F. Kearney, P. M. Lydyard, C. E. Gross, and A. R. Lawton. 1976. Studies of generation of B cell diversity in mouse, man and chicken. Cold Spring Harbor Symp. Quant. Biol. 41:139-145.

14. Cory, S., and J. M. Adams. 1980. Deletions are associated with somatic rearrangement of immunoglobulin heavy-chain genes. Cell 19:37-51.

15. Davis, M., K. Calame, P. Early, D. Livant, R. Joho, I. Weissman, and L. Hood. 1980. An immunoglobulin heavy-chain gene is formed by at least two recombinational events. Nature (London) 283:733-742.

16. Dunnick, W., T. H. Rabbitts, and C. Milstein. 1980. An immunoglobulin deletion mutant with implications for the heavy-chain switch and RNA splicing. Nature (London) 286:669-675.

17. Francus, T., B. Dharmgrongartma, R. Campbell, M. Scharff, and B. Birshtein. 1978. $\mathrm{IgG}_{2 \mathrm{a}}$-producing variants of an $\mathrm{IgG}_{2 \mathrm{~b}}$ producing mouse myeloma cell line. J. Exp. Med. 147:1535-1550.

18. Kataoka, T., T. Kawakami, N. Takahashi, and T. Honjo. 1980. Rearrangement of immunoglobulin $\gamma_{1}$-chain gene and mechanism for heavy-chain class. Proc. Natl. Acad. Sci. U.S.A. 77:919-923.

19. Kataoka, T., T. Miyata, and T. Honjo. 1981. Repetitive sequences in class-switch recombination regions of immunoglobulin heavy-chain genes. Cell 23:357-368.

20. Knapp, N. R., C. P. Strober, C. P. Liu, P. W. Tucker, N. Newell, and F. R. Blattner. 1981. Dual expression of IgM and IgD by a cloned $B$ cell line $\left(B C L_{1}\right)$ : a single copy of $V_{H}$ gene is shared by two adjacent $C_{H}$ genes, p. 19-26. In N. Kleinman, E. Mosier, I. Scher, and E. Vitetta (ed.), B lymphocytes in the immune response: functional development and integrative prop- erties. Elsevier/North-Holland Publishing Co., New York.

21. Lang, R. B., L. W. Stanton, and K. B. Marcu. 1982. On immunoglobulin heavy-chain gene switching: two $2 b$ genes are rearranged via switch sequences in MPC-11 cells but only one is expressed. Nucleic Acids Res. 10:611-630.

22. Lewis, S., N. Rosenberg, F. Alt, and D. Baltimore. 1982. Continuing kappa-gene rearrangement in a cell line transformed by Abelson murine leukemia virus. Cell 30:807-816.

23. Maki, R., A. Traunecker, H. Sakano, W. Roeder, and S. Tonegawa. 1980. Exon shuffling generates an immunoglobulin heavy chain gene. Proc. Natl. Acad. Sci. U.S.A. 77:2138-2142.

24. Marcu, K., R. Lang, L. Stanton, and L. Harrius. 1982. A model for the molecular requirements of immunoglobulin heavy chain class switching. Nature (London) 298:87-89.

25. Marcu, K., and M. Cooper. 1982. New views of the immunoglobulin heavy-chain switch. Nature (London) 298:327.

26. Maxam, A., and W. Gilbert. 1977. Sequencing end-labeled DNA with base-specific chemical cleavages. Proc. Natl. Acad. Sci. U.S.A. 74:560-564.

27. Moore, K., J. Rogers, T. Hunkapiller, P. Early, L. Nottenberg, I. Weissman, H. Bazin, and L. Hood. 1981. Expression of IgD may use both DNA rearrangement and RNA splicing mechanisms. Proc. Natl. Acad. Sci. U.S.A. 78:1800-1804.

28. Nikaido, T., S. Nakai, and T. Honjo. 1981. Switch region of immunoglobulin $\mathrm{C}_{\mu}$ gene is composed of simple tandem repetitive sequences. Nature (London) 292:845-848

29. Nikaido, T., Y. Yamawaki-Katauka, and T. Honjo. 1982. Nucleotide sequences of switch regions of immunoglobulin $C_{\varepsilon}$ and $\mathrm{C}_{\gamma}$ genes and their comparison. J. Biol. Chem. 25:7322-7329.

30. Neuberger, M., and F. Calabi. 1983. Reciprocal chromosome translocation between c-myc and immunoglobulin $2 \mathrm{~b}$ genes. Nature (London) 305:240-243.

31. Obata, M., T. Kataoka, S. Nakai, H. Yamagishi, N. Takahashi, Y. Yamawaki-Kataoka, T. Nakaido, A. Shimizu, and T. Honjo. 1981. Structure of a rearranged $\gamma_{1}$ chain gene and its implication to immunoglobulin class-switch mechanism. Proc. Natl. Acad. Sci. U.S.A. 78:2437-2441.

32. Pernis, B., L. Forni, and A. L. Luzzati. 1976. Synthesis of multiple immunoglobulin classes by single lymphocytes. Cold Spring Harbor Symp. Quant. Biol. 41:175-183.

33. Radbruck, A., B. Leisgang, and K. Rajewsky. 1980. Isolation of variants of mouse myeloma X63 that express changed immunoglobulin class. Proc. Natl. Acad. Sci. U.S.A. 77:2909-2913.

34. Rimm, D. L., D. Harness, J. Kucera, and F. R. Blattner. 1980. Construction of coliphage lambda Charon vectors with BamHI cloning sites. Gene 12:301-309.

35. Sakano, H., Y. Kurosawa, M. Weigert, and S. Tonegawa. 1981. Identification and nucleotide sequence of a diversity DNA segment (D) of immunoglobulin heavy chain genes. Nature (London) 290:562-565.

36. Sakano, H., R. Maki, Y. Kurosawa, W. Roeder, and S. Tonegawa. 1980. Two types of somatic recombination are necessary for the generation of complete immunoglobulin heavy-chain genes. Nature (London) 286:676-683.

37. Shimizu, A., and T. Honjo. 1984. Immunoglobulin class switching. Cell 36:801-803.

38. Shimizu, A., N. Takahashi, Y. Yaiota, and T. Honjo. 1982. Organization of the constant-region gene family of the mouse immunoglobulin heavy chain. Cell 248:499-506.

39. Stanton, L. W., and K. B. Marcu. 1982. Nucleotide sequence and properties of the murine $\gamma_{3}$ immunoglobulin heavy chain gene switch region: implications for successive $\mathrm{C}_{\gamma}$ gene switching. Nucleic Acids Res. 10:5993-6006.

40. Takahashi, N., T. Katoaka, and T. Honjo. 1980. Nucleotide sequences of class-switch recombination region of the mouse immunoglobulin $\gamma_{2 b}$-chain gene. Gene 11:117-127.

41. Van Ness, B., C. Coleclough, R. Perry, and M. Weigert. 1982. DNA between variable and joining gene segments of immunoglobulin $\mathrm{K}$ light chain is frequently retained in cells that rearrange the K locus. Proc. Natl. Acad. Sci. U.S.A. 79:262-266.

42. Yaiota, Y., and T. Honjo. 1980. Deletion of immunoglobulin heavy chain genes from expressed allelic chromosome. Nature (London) 286:850-853. 